\title{
Differential resilience of ancient sister lakes Ohrid and Prespa to environmental disturbances during the Late Pleistocene
}

\author{
Elena Jovanovska ${ }^{1}$, Aleksandra Cvetkoska ${ }^{2}$, Torsten Hauffe ${ }^{1}$, Zlatko Levkov ${ }^{3}$, Bernd Wagner ${ }^{4}$, Roberto Sulpizio ${ }^{5,6}$, \\ Alexander Francke ${ }^{4}$, Christian Albrecht ${ }^{1}$, and Thomas Wilke ${ }^{1}$ \\ ${ }^{1}$ Department of Animal Ecology and Systematics, Justus Liebig University, Giessen, Germany \\ ${ }^{2}$ Palaeoecology, Department of Physical Geography, Faculty of Geosciences, Utrecht University, Utrecht, the Netherlands \\ ${ }^{3}$ Institute of Biology, University Ss. Cyril and Methodius, Skopje, the Former Yugoslav Republic of Macedonia \\ ${ }^{4}$ Institute of Geology and Mineralogy, University of Cologne, Cologne, Germany \\ ${ }^{5}$ Dipartimento di Scienze della Terra e Geoambientali, Bari, Italy \\ ${ }^{6}$ IDPA-CNR, Milan, Italy \\ Correspondence to: Elena Jovanovska (jovanovska.eci@gmail.com)
}

Received: 2 September 2015 - Published in Biogeosciences Discuss.: 29 September 2015

Revised: 27 January 2016 - Accepted: 5 February 2016 - Published: 25 February 2016

\begin{abstract}
Ancient lakes, such as lakes Ohrid and Prespa on the Balkan Peninsula, have become model systems for studying the link between geological and biotic evolution. Recently, the scientific deep-drilling project Scientific Collaboration on Past Speciation Conditions in Lake Ohrid (SCOPSCO) was initiated to better understand the environmental, climatic, and limnological evolution of the lake. It revealed that Lake Ohrid experienced a number of environmental disturbances during its ca. 2.0 million year long history. These are comprised of disturbances that lasted over longer periods of time ("press events") such as glacial-interglacial cycles and Heinrich events, as well as sudden and short disturbances ("pulse events") like the deposition of landslides, earthquakes, and volcanic ash depositions. The latter includes one of the most severe volcanic episodes during the Late Pleistocene: the eruption of the Campanian Ignimbrite (known as Y-5 marine tephra layer) from the Campi Flegrei caldera, dated to $39.6 \pm 0.1$ thousand years ago. The event is recorded by the deposition of a ca. $15 \mathrm{~cm}$ thick tephra layer in sediment cores of lakes Ohrid (DEEP-5045-1) and Prespa (Co1204). Coincidently, this pulse event is superimposed by the Heinrich $\mathrm{H} 4$ event, 40.4-38.4 thousand years ago.

In the current paper, diatoms were used as proxies to compare the responses of these lakes to the Y-5 (pulse) and the H4 (press) disturbances. Based on stratigraphically constrained incremental sum of squares cluster (CONISS) and unconstrained Partitioning Around Medoids (PAM) analyses, we
\end{abstract}

found little evidence that diatom community compositions in either lake responded to the $\mathrm{H} 4$ event. However, the Y5 influx caused clear and rapid diatom community changes. After the initial response, community compositions in Lake Ohrid and, to a lesser extent, in Lake Prespa slowly returned to their quasi pre-disturbance state. Moreover, there is no evidence for disturbance-related extinction events. The combined evidence from these findings suggests that lakes Ohrid and Prespa likely did not experience regime shifts. It is therefore concluded that both lakes show resilience to environmental disturbance. However, it seems that Lake Ohrid is more resilient than Lake Prespa, as the recovery of diatom communities is more pronounced and its estimated recovery time is only ca. 1100 years vs. ca. 4000 years in Lake Prespa. The reasons for the differential responses remain largely unknown, but differences in geology, lake age, limnology, and intrinsic parameters of the diatom proxies may play an important role.

\section{Introduction}

Ancient lakes, i.e., extant lakes that have continuously existed since before the Last Glacial Maximum (Albrecht and Wilke, 2008), have become model systems for studying the link between geological and biological evolution over extended periods of time. For some ancient lakes, such as 
Baikal (Russia) and Hövsgöl (Mongolia), it has been demonstrated that the evolution of their species was largely shaped by massive environmental disturbances, like extreme lakelevel fluctuations and glacial-interglacial cycles (Karabanov et al., 2004).

However, for other ancient lakes, like the sister lakes Ohrid and Prespa on the Balkan Peninsula, the link between geological and biotic evolution is not well understood. In order to better understand the environmental, climatic, and limnological evolution of Lake Ohrid, the Scientific Collaboration on Past Speciation Conditions in Lake Ohrid (SCOP$\mathrm{SCO})$ project was initiated. Early results revealed that the lake experienced a number of environmental disturbances during its ca. 2.0 million year (Myr) long history (Lindhorst et al., 2015). Some of these events lasted over longer periods of time and covered, for example, glacial-interglacial cycles (Wagner et al., 2014) or Heinrich events (Wagner et al., 2010). The latter comprise episodes of massive iceberg discharges that caused cooling of the North Atlantic during the last glacial period (Bond et al., 1993). These events presumably intensified the aeolian activity, lowered the temperature, and increased the aridity in the Ohrid region (Wagner et al., 2010). From a biological perspective, long-lasting disturbances (> several centuries) are referred to as "press disturbances" (Niemi et al., 1990). In contrast, sudden disturbances with a short and clearly defined duration ( $<$ few decades) are called "pulse disturbances" (Niemi et al., 1990). Examples include landslides (Lindhorst et al., 2014), earthquakes (Hoffmann et al., 2010; Wagner et al., 2012b; Lindhorst et al., 2015), and volcanic ash depositions (Sulpizio et al., 2010; D'Addabbo et al., 2015).

The eruption of the Campanian Ignimbrite from the Campi Flegrei caldera, dated to $39.6 \pm 0.1$ thousand years (ka) ago, is considered to be one of the most severe volcanic events during the Late Pleistocene (De Vivo et al., 2001; Fedele et al., 2003; Costa et al., 2012; Fitzsimmons et al., 2013; Leicher et al., 2015). The corresponding Y-5 tephra plume dispersed across the Mediterranean and central Europe and even reached the Black Sea, the Russian plain, and the northern African coast (see Fig. 1a; Fitzsimmons et al., 2013). The tephra also discharged into lakes Ohrid and Prespa, directly through atmospheric precipitation and/or indirectly through catchment runoff. The volcanic event is recorded by a ca. $15 \mathrm{~cm}$ thick and well-preserved tephra layer in sediment cores of both lakes (Sulpizio et al., 2010; Wagner et al., 2012a; Leicher et al., 2015).

It has been suggested that the interaction of volcanic ash deposition with a receiving lake triggers perturbations, primarily through the effect of tephra weathering but also through changes in $\mathrm{pH}$, mineral concentration, organic matter input, and short-term light deprivation (e.g., Harper et al., 1986; Barker et al., 2003; Telford et al., 2004; Cruces et al., 2006; Urrutia et al., 2007; D'Addabbo et al., 2015). Depending on the magnitude of the disturbance and the resilience of the respective ecosystem (i.e., the amount of disturbance an

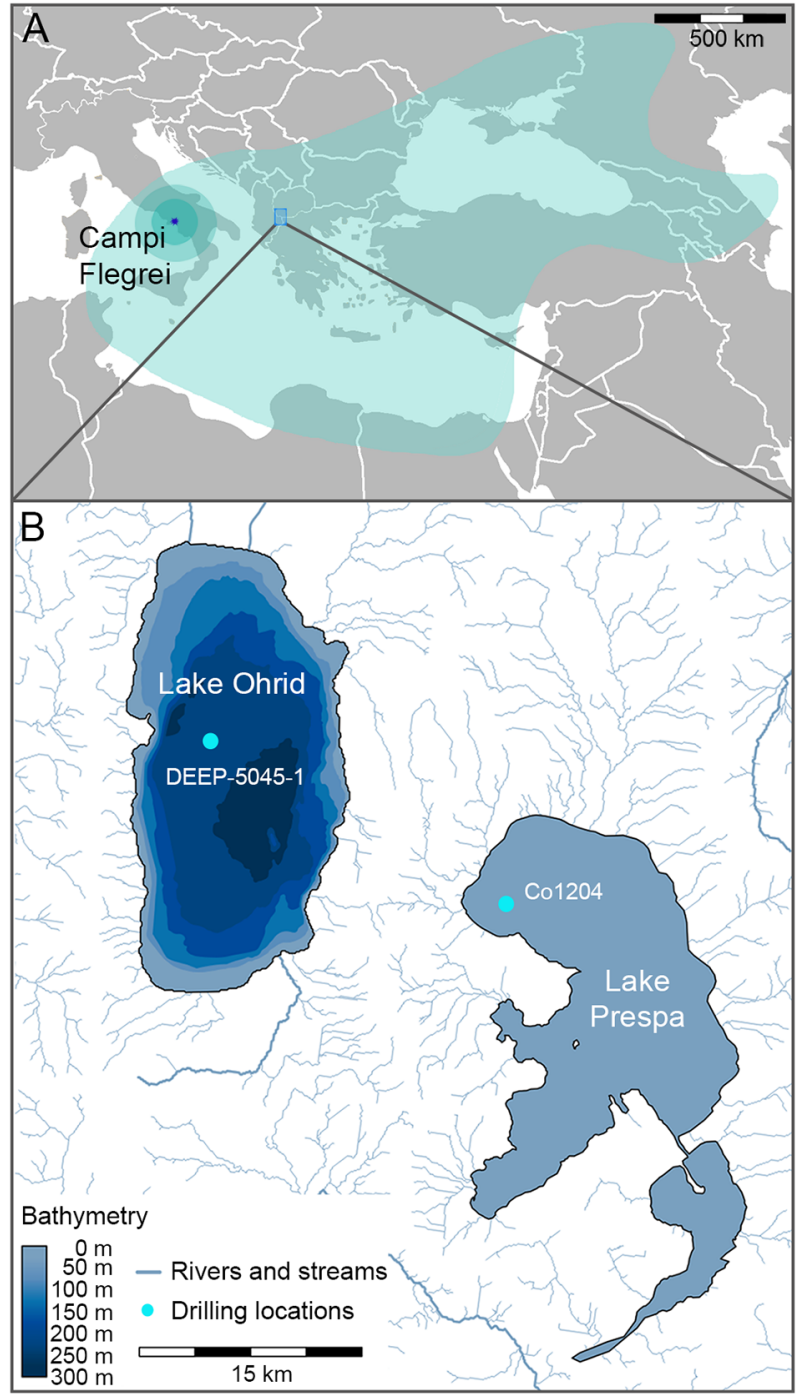

Figure 1. Maps showing (a) the Y-5 tephra distribution from the Campi Flegrei caldera (blueish-green shading; area as defined by Fitzsimmons et al., 2013) and (b) the drilling sites in lakes Ohrid (DEEP-5045-1) and Prespa (Co1204).

ecosystem can tolerate without changing its regime; Holling et al., 1973, 1986; Scheffer and Carpenter, 2003; Baho et al., 2014), lake biota may react with extinction events and/or changes in community structures and functions.

Some organisms, like diatoms (single-celled siliceous algae), react very sensitively to pulse disturbances, such as tephra depositions (e.g., Harper et al., 1986; Barker et al., 2003; Cruces et al., 2006). Moreover, they are remarkably well-preserved in the sediment records of lakes Ohrid and Prespa (e.g., Reed et al., 2010; Cvetkoska et al., 2012, 2014, 2015a; Zhang et al., 2016). These aspects make diatoms excellent proxies for studying how the lakes responded to environmental disturbances. In fact, previous sediment core analyses suggest alterations in diatom assemblage structure and 
abundances due to tephra influxes in both lakes (Cvetkoska et al., 2012, 2014, 2015a, b). However, the low temporal resolution did not allow the diatom data to be linked to distinct pulse events or used to estimate recovery periods (i.e., the time an ecosystem needs to return to pre-disturbance conditions; the recovery period serves as a measure of resilience strength; Carpenter, 2013). Therefore, it remains unclear how the lakes responded to such changes and whether there were differences in response.

Given this lack of knowledge, the general goal of this paper is to use diatom community data from the sediment records of lakes Ohrid (core DEEP-5045-1) and Prespa (core Co1204) as a proxy to comparatively study the responses of these lakes to one of the most severe pulse disturbance events during the late Pleistocene - the Y-5 tephra influx. Our specific objectives were to study

1. whether lakes Ohrid and Prespa had the resilience to tolerate this disturbance without changing their regimes (i.e., without exceeding a critical threshold). Operational criteria for resilience are the lack of disturbancerelated extinction events in the diatom record and a subsequent return of diatom communities to a quasi predisturbance state.

2. if resilience can be demonstrated for one or both lakes, whether there are differences in resilience strength between the two systems. The operational criterion for resilience strength is the length of the recovery period, which is measured as the time the diatom communities need to return to their quasi pre-disturbance state.

Lake Ohrid has long been considered to have a high level of ecosystem stability (Stanković, 1960; Föller et al., 2015), principally due to its depth, age, and peculiar karst limnology. Hence, our working hypothesis is that Lake Ohrid is more resilient to environmental disturbances than Lake Prespa.

Coincidently, the Y-5 tephra deposition $(39.6 \pm 0.1 \mathrm{ka})$ is superimposed by the Heinrich $\mathrm{H} 4$ event that occurred 40.4$38.4 \mathrm{ka}$ (see Wutke et al., 2015 for the temporal gap between Y-5 and H4) and left signatures in the sediment records of both lakes (Wagner et al., 2010; Panagiotopoulos et al., 2014; Cvetkoska et al., 2015b). This provides a unique opportunity to obtain information on the differential effect of a short pulse and longer press disturbance events.

We believe that this study can contribute to one of the major goals of the SCOPSCO deep-drilling program: to evaluate the influence of major geological events on the evolution of endemic taxa in Lake Ohrid (Wagner et al., 2014). It might also provide insight into the response of lakes to massive environmental disturbances.

\section{Material and methods}

\subsection{Site description}

The ancient lakes Ohrid and Prespa are located on the Balkan Peninsula (Fig. 1) within karstic steep-sided graben systems with a rift-formation origin (Stanković, 1960; Matzinger et al., 2006a; Albrecht et al., 2008). They are separated by the Galičica Mountain range but share an underground connection (Matzinger et al., 2006a).

Lake Ohrid is located at $693 \mathrm{~m}$ a.s.1., covers a surface area of $358 \mathrm{~km}^{2}$, and has a maximum water depth of $293 \mathrm{~m}$ (Lindhorst et al., 2014). The hydrological regime of the lake is highly regulated with inflow from karstic aquifers (sublacustrine and surface springs), while the outflow occurs via the Crni Drim river (Matzinger et al., 2006a). Oligotrophic Lake Ohrid is phosphorus limited (Allen and Ocevski, 1977), with an average total phosphorus (TP) concentration of $4.5 \mathrm{mg} \times \mathrm{m}^{-3}$ (Matzinger et al., 2007) and total nitrogen (TN) concentration of $171-512 \mathrm{mg} \times \mathrm{m}^{-3}$ (Watzin et al., 2002). The lake's silica (SI) concentration is $<200 \mathrm{mg} \times \mathrm{m}^{-3}$ in the trophogenic zone during summer (Stanković, 1960), while the average water $\mathrm{pH}$ and conductivity are 8.48 and $208 \mu \mathrm{S} \times \mathrm{cm}^{-1}$, respectively (Schneider et al., 2014). The average Secchi depth is ca. $14 \mathrm{~m}$ (Matzinger et al., 2006b).

Neighboring Lake Prespa is situated ca. $160 \mathrm{~m}$ above Lake Ohrid (849 ma.s.l.) and has a surface area of $254 \mathrm{~km}^{2}$ and a maximum water depth of $58 \mathrm{~m}$ (Matzinger et al., 2006a; Albrecht et al., 2008). The water balance is regulated through inputs from Lake Mikri Prespa, catchment and river runoff, groundwater, and direct precipitation. Water output occurs through karstic aquifers, irrigation, and water surface evaporation (Matzinger et al., 2006a). Mesotrophic Lake Prespa has an average TP concentration of $31 \mathrm{mg} \times \mathrm{m}^{-3}$ (Wagner et al., 2010), an average TN concentration of ca. $2000 \mathrm{mg} \times \mathrm{m}^{-3}$, an average water $\mathrm{pH}$ of ca. 8.3, and an average Secchi depth of ca. $2.6 \mathrm{~m}$ (Levkov et al., 2007).

\subsection{Core recovery and geochronology}

During the SCOPSCO deep-drilling campaign in spring 2013, a $569 \mathrm{~m}$ long core (DEEP-5045-1) was retrieved from the central part of the Ohrid Basin at ca. $243 \mathrm{~m}$ water depth (Fig. 1b; Wagner et al., 2014). To date, only sediments of the upper $247.8 \mathrm{~m}$ composite depth (mcd) of the DEEP site sequence have become available (Francke et al., 2016). The age-depth model of the composite sequence, which is based on 11 tephrostratigraphic tie points (first-order tie points) and on tuning of biogeochemical proxy data to orbital parameters (second-order tie points), suggest that this sequence covers the last $637 \mathrm{kyr}$ (Baumgarten et al., 2015; Francke et al., 2016). In this study, we focused on the Y-5 tephra layer at $39.6 \pm 0.1 \mathrm{ka}$, according to the age estimations provided by Leicher et al. (2015). 
The Lake Prespa core (Co1204) was recovered in October 2011 from the northwestern part of the lake (Fig. 1b; Wagner et al., 2010). The age model of the $17.76 \mathrm{~m}$ long sequence was established using radiocarbon dating of macrofossil remains, as well as three major tephra layers as control points. The resulting age model covers ca. $48 \mathrm{kyr}$ (Sulpizio et al., 2010; Wagner et al., 2010).

\subsection{Diatom analyses}

In total, 193 sediment subsamples were collected and analyzed from the Ohrid and Prespa cores (18.19-14.19 and 9.21-7.47 mcd, respectively). In the Prespa core, the tephra boundaries were sharp and clearly distinguishable. In the Ohrid core, only the lower boundary was clear; the upper boundary appeared relatively diffuse, presumably due to post-depositional tephra input from the catchment area, bioturbation, and/or drilling artefacts. Within and around the actual tephra layer, the cores were sliced in $5 \mathrm{~mm}$ intervals, corresponding to a temporal resolution of approximately 10 years. With increasing distance above and below the tephra layer, resolution was decreased first to 4 and then to $16 \mathrm{~cm}$.

For diatom analyses, weighed samples of freeze-dried sediments were acid-cleaned with cold $35 \% \mathrm{H}_{2} \mathrm{O}_{2}$ and $10 \%$ $\mathrm{HCl}$ and left overnight for the removal of carbonates. The samples were then boiled in a water bath for $2 \mathrm{~h}$ in $37 \%$ $\mathrm{HCl}$ for oxidization of the organic matter (Renberg, 1990; Cvetkoska et al., 2012). The treated samples were rinsed several times with distilled water and subsequently centrifuged to remove the products of the oxidation reaction. Defined aliquots of the cleaned samples were settled onto coverslips and then mounted on glass slides using Naphrax ${ }^{\circledR}$. In each sample, random transects were selected and 200-400 diatom valves per slide were counted and identified at $1000 \times$ magnification with a Carl Zeiss, Axioplan 2 microscope, equipped with a Nikon D5700 digital camera. All samples and microscopic slides are hosted at the University of Giessen Systematics and Biodiversity Collection (UGSB), Department of Animal Ecology and Systematics, Justus Liebig University, Giessen, Germany. Diatom identification followed Levkov et al. (2007), Levkov and Williams (2011), Cvetkoska et al. (2012, 2014), Jovanovska et al. (2013), and Pavlov et al. (2013).

Diatom counts were converted to percentages and displayed using the package rioja 0.9.3 (Juggins, 2014) for the $\mathrm{R}$ statistical environment 3.2.1 (R Core Team, 2015). For characterizing diatom-based stratigraphic zones, a constrained incremental sum of squares cluster analysis (CONISS; Grimm, 1987) was performed in rioja.

In addition, we determined community response phases based on distinct changes in community structures using the stratigraphically unconstrained clustering approach of Partitioning Around Medoids (PAM; Kaufman and Rousseeuw, 1990). PAM clusters pairwise Bray-Curtis dissimilarities (Bray and Curtis, 1957) of communities into $k$ groups of minimum intragroup sum of distances, with an optimum of $k$ chosen by the silhouette criterion (Kaufman and Rousseeuw, 1990). The PAM analyses were performed with the package cluster 2.0.3 (Maechler et al., 2013) for R. Using BrayCurtis dissimilarities, we performed a metric multidimensional scaling in $\mathrm{R}$ and plotted the scores of the first axes according to their respective age.

Recovery times were calculated by estimating the time differences between the same group memberships assigned by the PAM analyses before and after the tephra influx. As the diatom communities sampled in Lake Ohrid are biased towards planktonic species due to the deep-water coring location, we determined recovery times both for planktonic and overall communities in lakes Ohrid and Prespa.

\section{Results}

In total, 94 and 213 diatom species were identified in the cores of lakes Ohrid and Prespa, respectively. Due to the difference in water depth of the coring locations (ca. $243 \mathrm{~m}$ for Lake Ohrid vs. $14 \mathrm{~m}$ for Lake Prespa), planktonic species were dominant in Lake Ohrid, especially members of the genus Cyclotella. Though many benthic species were found, they only occurred in low abundance. In contrast, planktonic and benthic species in Lake Prespa were roughly balanced (Figs. 2 and 3).

Some planktonic species showed a high morphological variability with respect to valve size, shape of the central area, and number of ocelli in the central area (e.g., $C y$ clotella fottii and Cyclotella ocellata). In order to fully cover the magnitude of potential community changes, we assigned them to distinct morphotypes and identification units (see Figs. 2 and 3).

\subsection{Identification of community response phases and diatom zones}

The stratigraphically unconstrained PAM analyses identified three major community response phases in lakes Ohrid and Prespa: a phase that corresponds to pre-disturbance conditions (pre-tephra-disturbance phase; Fig. 4; also see the lower blue bars in Figs. 2 and 3), a distinct disturbance phase (tephra-disturbance phase; Fig. 4; also see the green and yellow bars in Figs. 2 and 3), and a phase in which communities had returned to quasi pre-disturbance conditions (posttephra-disturbance phase; Fig. 4; also see the upper blue bars in Figs. 2 and 3).

The stratigraphically constrained CONISS analyses identified three distinct diatom zones together with several subzones each for lakes Ohrid (ODZs) and Prespa (PDZs). They largely corresponded to the pre-tephra-disturbance phase (ODZ 3b-a and PDZ 3b-a), the tephra-disturbance phase (ODZ 2b-a and PDZ 2, 1d-b), and the post-tephra- 


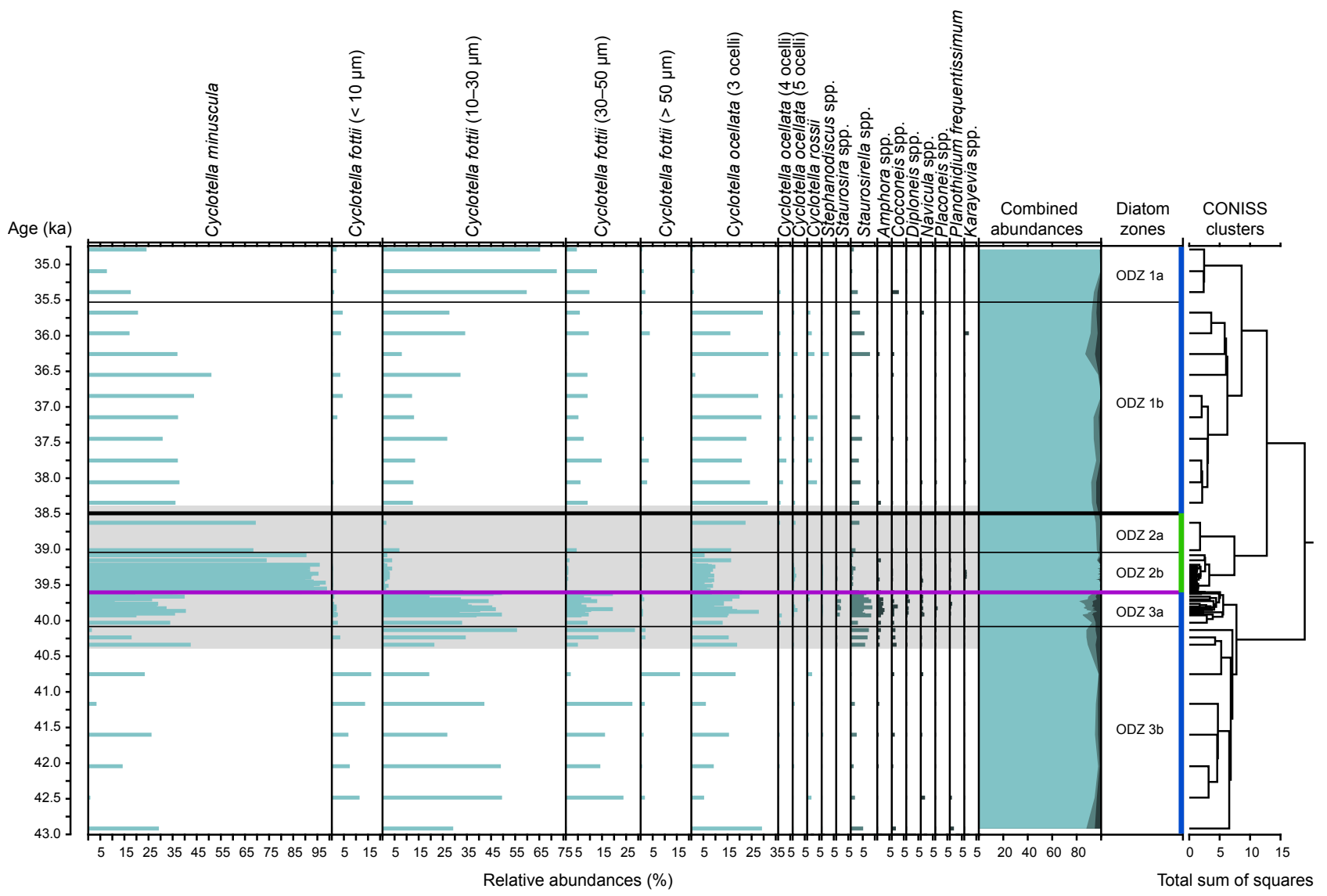

Figure 2. Summary diatom diagram for the Ohrid core (DEEP-5045-1). Only diatom taxa with relative abundances of $>2 \%$ are shown. Individual abundances are color-coded according to lifestyle (light blueish green: planktonic; medium greyish green: facultative planktonic; dark greyish green: benthic). Diatom zones and subzones were defined by CONISS; zone boundaries are represented with thick solid lines, subzone boundaries with thin solid lines. PAM community clusters are color-coded according to Fig. 4a. The purple line indicates the timing of the Y-5 eruption; the grey-shaded area the duration of the H4 event. Note that the diatom communities had reached the quasi pre-disturbance state (upper blue bar) before the end of the $\mathrm{H} 4$ event.

disturbance phase (ODZ 1b-a and PDZ 1a) (see Figs. 2 and $3)$.

\subsection{Diatom analyses of the Ohrid core}

\subsubsection{Pre-tephra-disturbance phase (ODZ 3b-a; date 43.00-39.60 ka)}

Diatom subzones ODZ 3b-a (Fig. 2) were characterized by the presence of the planktonic taxa Cyclotella fottii, C. ocellata complex, and $C$. minuscula, of which $C$. fottii was the most dominant with up to $50 \%$ relative abundance. In contrast, the benthic and facultative planktonic species had abundances of up to $10 \%$ when taking the whole profile into account. Examples include Staurosirella spp., Staurosira spp., Amphora spp., Cocconeis spp., Diploneis spp., Planothidium frequentissimum, and Navicula spp.

\subsubsection{Tephra-disturbance phase (ODZ 2b-a; date $39.60-38.50 \mathrm{ka})$}

Within ODZ 2b, C. fottii and C. ocellata were replaced by C. minuscula (Fig. 2), which reached almost $100 \%$ relative abundance. Abundances of facultative planktonic and benthic species (e.g., Navicula spp., Diploneis spp., Staurosirella spp.) gradually decreased to values $<5 \%$. The subzone ODZ $2 \mathrm{a}$ is marked by the absence of benthic species and the slight decline in C. minuscula to ca. $70 \%$ relative abundance.

\subsubsection{Post-tephra-disturbance phase (ODZ 1b-a; date $38.50-34.75 \mathrm{ka})$}

Diatom subzone ODZ $1 \mathrm{~b}$ (Fig. 2) is marked by a decline in Cyclotella minuscula down to ca. $20 \%$, reaching a relative abundance of $10 \%$ towards the upper subzone boundary ODZ 1 a. In contrast, $C$. fottii and $C$. ocellata gradually increase in abundance to 75 and $30 \%$, respectively. The lat- 


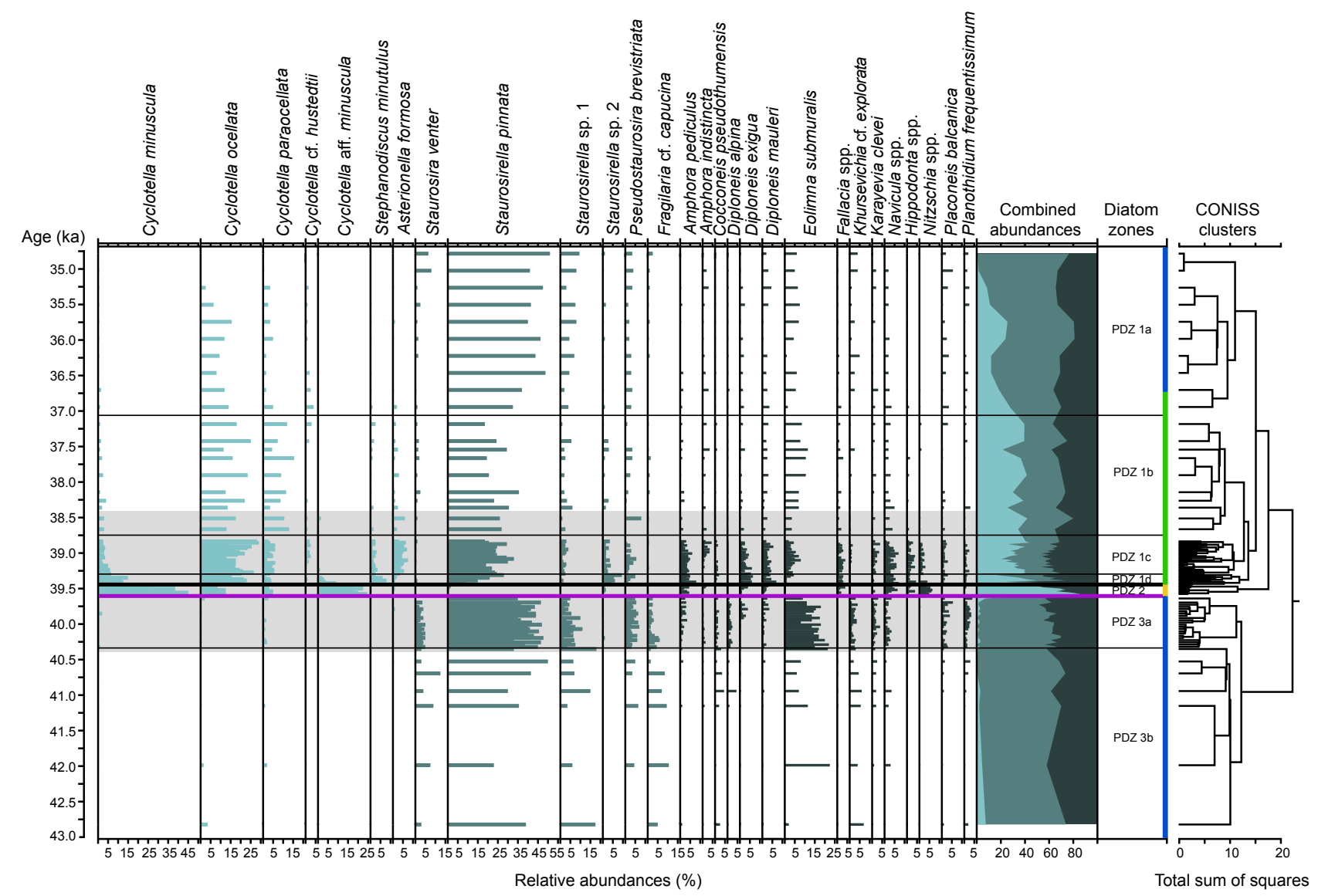

Figure 3. Summary diatom diagram for the Prespa core (Co1204). Only diatom taxa with relative abundances of $>4 \%$ are shown. Individual abundances are color-coded according to lifestyle (light blueish green: planktonic; medium greyish green: facultative planktonic; dark greyish green: benthic). Diatom zones and subzones were defined by CONISS; zone boundaries are represented with thick solid lines, subzone boundaries with thin solid lines. PAM community clusters are color-coded according to Fig. $4 \mathrm{~b}$. The purple line indicates the duration of the Y-5 eruption; the grey-shaded area the timing of the H4 event. Note that the diatom communities had reached the quasi pre-disturbance state (upper blue bar) only after the end of the H4 event.

ter decreased to $<5 \%$ in ODZ 1a. The facultative planktonic taxa, especially Staurosirella spp., were present at abundances of ca. $5 \%$ in ODZ $1 \mathrm{~b}$ and gradually decreased to ca. $2 \%$ relative abundance towards the upper ODZ 1a boundary. The combined abundances of benthic species remained low at $<2 \%$, almost disappearing in ODZ 1 a.

\subsection{Diatom analyses of the Prespa core}

\subsubsection{Pre-tephra-disturbance phase (PDZ 3b-a; date $43.00-39.60 \mathrm{ka})$}

The diatom assemblages of this zone were dominated by facultative planktonic species (e.g., Staurosirella pinnata, Staurosira venter, and Pseudostaurosira brevistriata) and the benthic species Eolimna submuralis (Fig. 3). The latter reached relative abundances between 5 and $20 \%$. The planktonic species $C$. minuscula was present at ca. $2 \%$ abundance in PDZ 3a, while the benthic species were consistently low in abundance.

\subsubsection{Tephra-disturbance phase (PDZ 2, PDZ 1d-b; date 39.60-37.00 ka)}

In zone PDZ 2, facultative planktonic species (e.g., S. pinnata, Staurosirella sp. 1, Fragilaria cf. capucina, and P. brevistriata) were replaced by planktonic species (e.g., C. minuscula $\leq 50 \%, C$. ocellata $\leq 30 \%$, and C. paraocellata $\leq 5 \%$ relative abundances). Note that Cyclotella aff. minuscula had relative abundances of up to $30 \%$. Most benthic species decreased in abundance (e.g., E. submuralis, Placoneis balcanica, Khursevichia cf. explorata), and only few increased (e.g., Fallacia spp., Hippodonta spp., Nitzschia spp., and Navicula spp.).

Subzones PDZ 1d-b are characterized by a decline in $C$. minuscula abundances to $<5 \%$ and a renewed dominance of facultative planktonic and benthic species. However, some 

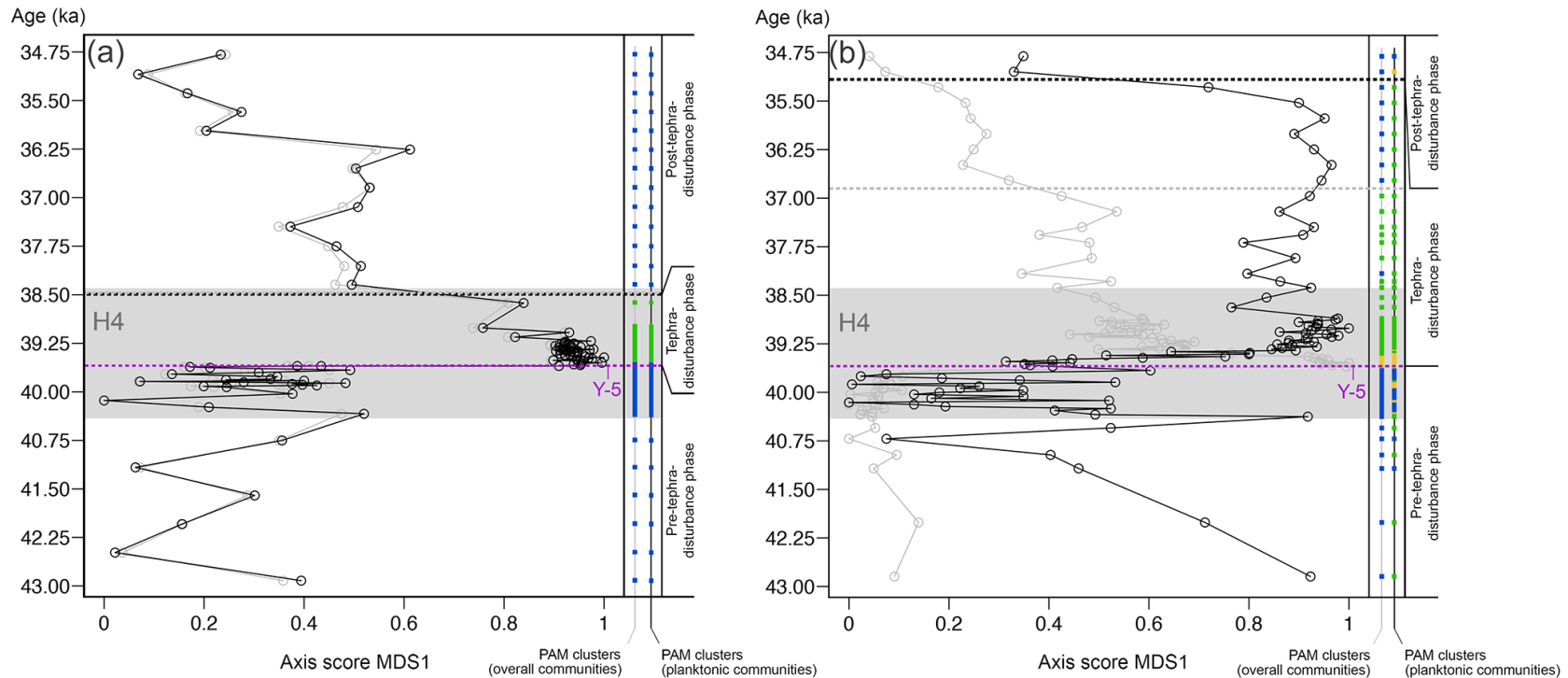

Figure 4. Diagrams showing changes in MDS (multidimensional scaling) diatom community compositions (black curves: planktonic communities; grey curves: overall communities) and respective PAM community assignments (colored bars for lakes Ohrid (a) and Prespa (b). The purple dashed lines indicate the timing of the Y-5 eruption, the grey areas the timing of the H4 event, and the black and grey dashed lines the return of the respective planktonic and overall community compositions to quasi pre-disturbance state.

planktonic species maintained their abundances throughout PDZ 1d-b. Cyclotella aff. minuscula sharply decreased in subzone PDZ 1d and almost disappeared in PDZ 1c-b. Asterionella formosa and $S$. minutulus increased in abundance in subzone PDZ 1c and decreased in subzone PDZ 1b. The planktonic $C$. ocellata and $C$. paraocellata, and the benthic E. sumburalis increased their relative abundances in subzones PDZ 1c-b.

\subsubsection{Post-tephra-disturbance phase (PDZ 1a; date $37.00-34.75 \mathrm{ka})$}

The diatom subzone PDZ 1a is characterized by a gradual decline in planktonic species (e.g., C. paraocellata and $C$. ocellata), dropping to $<2 \%$ relative abundances in the upper part of this subzone. Cyclotella minuscula decreased to an abundance of $<2 \%$ at the upper subzone boundary. In contrast, benthic species moderately increased in their abundances with only few decreasing (e.g., Hippodonta spp., Fallacia spp., Nitzschia spp.).

\subsection{Community composition analyses and estimations of recovery times}

The first ordination axis of the metric multidimensional scaling analyses indicates that the Y-5 tephra deposition caused very rapid changes in the diatom communities of lakes Ohrid (Fig. 4a) and Prespa (Fig. 4b). Given that the communities in Lake Ohrid's DEEP core were dominated by planktonic species, the respective curves for overall (i.e., planktonic and benthic communities) and planktonic communities in Fig. 4a showed similar patterns over time. After the drastic change in community composition, coinciding with the tephra deposition, communities reverted to a quasi pre-disturbance state (green bar in Fig. 2).

In Lake Prespa, where planktonic and benthic species were roughly balanced, the overall community structure (grey curve in Fig. 4b) rapidly changed, following the Y-5 event and then gradually approached a quasi pre-disturbance state. Both the stratigraphically unconstrained PAM and the constrained CONISS analyses suggest recovery through a direct and prolonged phase (see the yellow and green bars on Figs. 3 and 4). PAM suggests a recovery period until the beginning of subzone PDZ 1a, while CONISS suggests a recovery period until subzone PDZ 1a. For the planktonic communities of Lake Prespa, the change coinciding with the tephra deposition was not as abrupt and the return to the preeruption community state occurred more gradually.

The diatom communities in both lakes Ohrid and Prespa did not display a strong response to the onset of the $\mathrm{H} 4$ event at $40.4 \mathrm{ka}$. In Lake Ohrid, H4-specific PAM clusters or CONISS zones could not be detected. However, in Lake Prespa a distinct CONISS subzone coincides with H4 (see Fig. 3).

The Ohrid communities had converted back to the quasi pre-disturbance state shortly before the cessation of the $\mathrm{H} 4$ event at $38.4 \mathrm{ka}$ (see grey and black dashed lines in Fig. 4a; also see the upper blue bar in Fig. 2), whereas this process in the Prespa communities extended beyond the end of the Heinrich event (see grey and black dashed lines in Fig. 4b; also see the upper blue bar in Fig. 3). The PAM analyses 
clearly showed that the Ohrid and Prespa communities did return to their quasi pre-disturbance states (see the upper blue bars in Figs. 2 and 3 and the PAM clusters in Fig. 4), indicating that no regime shift occurred.

According to the age models of the two cores, the recovery times (i.e., the time differences between the same group membership assigned by the PAM analyses before and after the tephra influx) for planktonic communities in lakes Ohrid and Prespa were ca. 1100 and ca. 4000 years, respectively (Fig. 4), following the Y-5 tephra influx.

\section{Discussion}

Our results indicated only mild effects of the $\mathrm{H} 4$ event on diatom community compositions in lakes Ohrid and Prespa, though the impact is slightly greater in the latter. In contrast, the Y-5 influx caused clear and rapid responses in both lakes (Fig. 4). The overall community composition in Lake Prespa partially recovered within a few decades. This was mostly driven by benthic species. The community composition then slowly returned to the quasi pre-disturbance state over an extended period of time, while the planktonic community required a longer period of time for recovery (compare the grey and black curves in Fig. 4b). By contrast, in Lake Ohrid, both overall and planktonic community composition indicated similar reactions to the Y-5 tephra influx (Fig. 4a), owing to the fact that planktonic communities strongly dominated in the lake due to the depth of the drilling location.

When comparing changes in planktonic communities in lakes Ohrid and Prespa, the overall patterns are similar. An initial rapid response phase was followed by a phase in which communities slowly returned to the quasi pre-disturbance state. However, as noted above, the quasi pre-disturbance state in the Ohrid communities was reached shortly before the $\mathrm{H} 4$ cessation, whereas the Prespa communities recovered only long after the end of the Heinrich event.

\subsection{Diatom responses to disturbances in Lake Ohrid}

The communities in the Ohrid core were mainly characterized by planktonic species (Fig. 2). Although at low abundances, the benthic species likely indicate wind-induced water currents, water mixing, and/or sediment redistribution in the lake (cf. Vogel et al., 2010b; Cvetkoska et al., 2015a). The latter process might explain the prevalence of benthic species at $243 \mathrm{~m}$ water depth. Almost all of the identified benthic taxa have been reported from contemporary communities in the littoral zones (0-60 m water depth) of Lake Ohrid (Levkov et al., 2007; Levkov and Williams, 2012; Jovanovska et al., 2013; Pavlov et al., 2013). The benthic species slightly increased in abundance with the onset of the $\mathrm{H} 4$, indicating the possibility of intensified wind transport and mixing of the water column during the $\mathrm{H} 4$ stadial (40.4-38.4 ka). However, distinct changes in community composition were not revealed. The minor influence of the $\mathrm{H} 4$ event on Lake Ohrid is also reflected in the previously published geochemical data (Wagner et al., 2010).

In contrast to the onset of this press disturbance event, the Y-5 pulse disturbance event triggered an immediate reaction by the lake's diatom communities. The deposition of silicarich volcanic ashes (ca. $60 \% \mathrm{SiO}_{2}$; Sulpizio et al., 2010) likely had an impact on the water chemistry by increasing the silica content in the water column (D'Abbabbo et al., 2015). Indications of these changes are the rapid replacement of the dominant hypolimnetic $C$. fottii with the epilimnetic C. minuscula (Fig. 2). The latter species (only 3-7 $\mu \mathrm{m}$ in diameter) has high silica incorporating rates and low-transparency preferences, which makes it a strong competitor for light and nutrients under tephra-altered environmental conditions (Cvetkoska et al., 2014, 2015a; Zhang et al., 2015). These conditions were temporally maintained before communities gradually returned to the quasi pre-disturbance state. During the recovery period (until ODZ $1 \mathrm{~b}$ ), the nutrient pool of the lake likely changed, yet continued silica enrichment from the catchment area may still have played a role. During the recovery period, $C$. minuscula slightly decreased in abundance, whereas other planktonic species maintained their elevated abundances until ODZ $1 \mathrm{~b}$.

The point of return to the quasi pre-disturbance state was probably reached in subzone ODZ 1b, when nutrient levels in the water column likely had recovered and silica levels had decreased. This is indicated by the increase in abundances of the endemic $C$. fottii to pre-tephra-disturbance levels. As the recovery of planktonic communities was achieved prior to the end of the $\mathrm{H} 4$ event (ca. 1100 years), we suggest that this press disturbance possibly amplified the impact of the Y-5 and prolonged the recovery but did not prevent it.

\subsection{Diatom responses to disturbances in Lake Prespa}

In contrast to the diatom communities in the Ohrid core, Prespa communities were characterized by significant abundances of both planktonic and benthic species. During the pre-tephra-disturbance phase (42.9-39.6 ka), the ordination (Fig. 4b) indicates only little change in overall community composition. However, planktonic communities did show moderate fluctuations in structure even before the onset of the $\mathrm{H} 4$ event at $40.4 \mathrm{ka}$. Moreover, the geochemical properties of the lake changed only moderately with the onset of the H4 (Wagner et al., 2010). Therefore, it remains difficult to quantify the immediate community impact of this press disturbance event.

The Y-5 associated silica fallouts (PDZ 2) rapidly altered the water chemistry by increasing the silica content (ca. $60 \%$ $\mathrm{SiO}_{2}$ in the tephra layer; Sulpizio et al., 2010) in the water column and likely affected the nutrient pool in the lake. The increased silica content favored the growth of planktonic species like C. minuscula, C. ocellata, C. paraocellata, and $C$. aff. minuscula. The latter taxon has never been reported 
before. It occurs exclusively during the recovery period and failed to establish permanently.

In contrast to the planktonic species, epiphytic and facultative planktonic species like Cocconeis pseudothumensis, Staurosirella pinnata, and Pseudostaurosira brevistriata temporally decreased in relative abundance for a period of few decades. This may be explained by a short-term destruction of the littoral macrophytic habitats as a result of the Y-5 influx.

In subzone PDZ 1d, nutrient levels likely increased in the water column, favoring species with high phosphorus and silica preferences, such as Stephanodiscus minutulus (Kilham et al., 1986). Due to increased nutrient availability and water transparency (Cvetkoska et al., 2014, 2015b), benthic species (e.g., Diploneis exigua, Placoneis balcanica, Karayevia clevei) increased in abundances. Moreover, the increased relative abundance of Asterionella formosa in subzone PDZ 1c indicates nutrient pool recovery (Holm and Armstrong, 1981). However, the overall community structure did not return to the pre-disturbance state until PDZ 1a (see the upper blue bar in Fig. 3).

This long recovery period for planktonic communities of almost 4000 years (exceeding the end of the $\mathrm{H} 4$ event) is striking and may reflect the joint impact of a press (H4) and a pulse (Y-5) event. Although we see a little effect at the initiation of the $\mathrm{H} 4$ event, it probably amplified the Y-5 impact and prolonged the recovery period of diatom communities in Lake Prespa. The combined effects of the H4 and Y-5 events are corroborated by previously published palynological data (Panagiotopoulos et al., 2014).

Interestingly, Cvetkoska et al. (2014) found evidence that the $\mathrm{H} 2, \mathrm{H} 5$, and $\mathrm{H} 6$ events influenced the diatom communities in Lake Prespa. However, their low-resolution study could not disentangle the almost simultaneous impacts of the $\mathrm{H} 4$ and $\mathrm{Y}-5$ events.

From the current study, it becomes clear that the changes in community composition are largely caused by the Y-5 event. However, relating our data to those of Cvetkoska et al. (2015a), we suggest that Heinrich and volcanic events, which are very different in nature, may drive communities in different directions.

\subsection{Disturbance-related regime shifts in diatom communities}

The first specific objective of this study was to evaluate whether lakes Ohrid and Prespa had the resilience to tolerate environmental disturbances without changing their regimes (i.e., without exceeding a critical threshold sensu Scheffer and Carpenter, 2003). Our operational criteria for assessing resilience were (i) the lack of disturbance-related extinction events in the diatom records and (ii) a subsequent return of diatom communities to their quasi pre-disturbance state.

The data obtained were informative in this regard. For instance, we do not see extinction events directly related to the
H4 and/or Y-5 events (see Figs. 2 and 3). Moreover, community compositions appear to subsequently return to their quasi pre-disturbance states (see Fig. 4a, b). However, whereas the latter patterns are clear for both overall and planktonic communities in Lake Ohrid as well as for overall communities in Lake Prespa, the return to the quasi pre-disturbance state in planktonic communities in Lake Prespa is less obvious (see the black curve in Fig. 4b). Accordingly, neither lake underwent regime shifts. We, therefore, conclude that lakes Ohrid and Prespa have a high ecosystem resilience. This is in contrast to findings from some lakes where instability was hypothesized due to increased susceptibility to regime shifts (cf. Spanbauer et al., 2014).

However, the drivers for the resilience in lakes Ohrid and Prespa remain unclear at this stage. They are likely multifactorial, involving parameters such as water depth, hydrological regime, and chemical buffer processes. As the resilience of the lakes was indirectly inferred using diatom communities as proxies, the results were likely also affected by intrinsic biotic parameters of the diatoms.

\subsection{Differential resilience in lakes Ohrid and Prespa}

Given that ecosystem resilience has been demonstrated for both lakes, our second specific objective was to investigate whether there were differences in resilience strength between the two systems. As an operational criterion for resilience strength, we used the length of the recovery periods (sensu Carpenter, 2013). Our working hypothesis was that Lake Ohrid is more resilient to environmental disturbances than Lake Prespa.

Concluding from the length of the recovery periods, Lake Ohrid is more resilient than Lake Prespa (ca. 1100 years vs. ca. 4000 years, respectively). The reasons for the differential responses of the two neighboring lakes remain less well understood (also see Wagner et al., 2010; Leng et al., 2013) but, as discussed above, may be related to differences in their geology, limnology, and lake age.

\subsection{Limitations and outlook}

We believe that the data and conclusions provided in the present paper are robust. The analyses showed that the diatom communities in both lakes recovered after major environmental disturbances and that there are differences in recovery times between the two lakes.

Nonetheless, given the nature of our data, a number of limitations have to be noted. Firstly, the resolution of the age models used and potential bioturbation may hamper the precise estimation of community change above and below the actual tephra deposition. Additionally, our findings are based on single core locations in lakes Ohrid and Prespa. Moreover, as former littoral core sediments from Lake Ohrid were characterized by the presence of hiatuses (e.g., Wagner et al., 2008; Vogel et al., 2010a), we had to use a core that was re- 
trieved from a greater water depth (see Fig. 1). This, in turn, resulted in a bias in the Ohrid communities towards planktonic species. Finally, our study lacked high-resolution geochemical core data for the time frame of interest.

In order to mitigate these problems, we used relative time information (i.e., diatom zones) for describing community changes, whenever possible. In the comparative resilience and recovery time analyses, we focused on changes in the planktonic communities, as they were directly comparable in the two lakes (see black curves in Fig. 4). We also used previously published Y-5 geochemical data, especially $\mathrm{SiO}_{2}$ content in the tephra layers (Sulpizio et al., 2010).

Despite these limitations, the response curves for the planktonic diatom communities in Ohrid and Prespa were similar. Differences mainly concerned the duration of the individual phases of community response. We take this as another indication for the robustness of our data.

Nevertheless, given the interesting and partly unexpected patterns observed, we encourage future projects that aim at studying resilience processes in lakes Ohrid and Prespa in more detail. This would not only be of interest from a conceptual but also from an applied point of view relative to current and future human impact scenarios for these model lakes (e.g., Kostoski et al., 2010).

In particular, we recommend high-resolution studies of more and other pulse and press disturbance events (e.g., earthquakes, lake-level fluctuations, orbital-suborbital climate changes) in order to better understand the interplay of multiple disturbances. Given the unexpectedly long recovery times found in this study, we also suggest studying postdisturbance patterns at a higher resolution and over extended periods of time.

\section{Conclusions}

In the present study, we demonstrated that diatom communities in ancient lakes Ohrid and Prespa reacted strongly to one of the most severe volcanic eruptions in the central Mediterranean region during the Late Pleistocene - the Y-5 event $(39.6 \pm 0.1 \mathrm{ka})$. After a rapid initial response, community compositions slowly returned to their quasi pre-disturbance states. In contrast to the Y-5 pulse disturbance event, signatures of the superimposed $\mathrm{H} 4$ press disturbance event were less distinct. However, the latter likely contributed to the extended recovery periods of $>1000$ years seen in both lakes. In the case of Lake Prespa, the $\mathrm{H} 4$ event may have prolonged full recovery from the Y-5 pulse event until after the end of the $\mathrm{H} 4$.

Nonetheless, the data suggest that the communities in lakes Ohrid and Prespa likely did not experience regime shifts (but see above for the complex pattern in planktonic communities in Lake Prespa). We, therefore, conclude that both lakes show a high resilience to environmental disturbances. However, the estimated recovery times, which can be used as measure for resilience strength, differed between lakes Ohrid and Prespa (i.e., ca. 1100 vs. ca. 4000 years, respectively). This finding supports our working hypothesis that Lake Ohrid is more resilient to environmental disturbances than Lake Prespa. The exact reasons for the differential responses remain unknown, but differences in geology, lake age, limnology, as well as intrinsic parameters of the diatom proxies may play an important role.

We do note some limitations of our study, such as the resolution of the age models and the different depths of the drilling locations, causing a bias towards planktonic species in Lake Ohrid. Nonetheless, we believe that the results presented here are robust as indicated by similar response curves for the overall communities in lakes Ohrid and Prespa. However, the curves for the planktonic communities show less similarity due to the complex response of Lake Prespa.

We also believe that this study provides important new insights into the response of ancient lakes to (multiple) environmental disturbances. Moreover, it contributes to one of the main goals of the SCOPSCO deep-drilling program: to evaluate the influence of major geological events on the evolution of endemic taxa in Lake Ohrid.

Author contributions. E. Jovanovska, C. Albrecht, and T. Wilke conceived the study. E. Jovanovska and A. Cvetkoska conducted the lab work. E. Jovanovska counted and identified all diatom valves and E. Jovanovska, A. Cvetkoska, and T. Hauffe performed the community analyses. The manuscript was written by E. Jovanovska and T. Wilke with contributions from all coauthors. All authors gave final approval for publication.

Acknowledgements. This project was supported by the German Research Foundation (DFG) grants WI 1902/13 and AL 1076/9 to T. Wilke and C. Albrecht, respectively. The SCOPSCO Lake Ohrid drilling campaign was funded by ICDP, the German Ministry of Higher Education and Research, the German Research Foundation, the University of Cologne, the British Geological Survey, the INGV and CNR (both Italy), and the governments of the Former Republic of Macedonia (FYROM) and the Republic of Albania. Logistic support was provided by the Hydrobiological Institute in Ohrid. Drilling was carried out by Drilling, Observation and Sampling of the Earth's Continental Crust's (DOSECC) and using the Deep Lake Drilling System (DLDS). Special thanks are due to Beau Marshall and the drilling team. Ali Skinner and Martin Melles provided immense help and advice during logistic preparation and the drilling operation. We sincerely thank Jane Reed for her valuable comments on a previous version of the manuscript. We also acknowledge the constructive and very helpful comments of the two referees.

Edited by: J. Middelburg 


\section{References}

Albrecht, C. and Wilke, T.: Ancient Lake Ohrid: biodiversity and evolution, Hydrobiologia, 615, 103-140, 2008.

Albrecht, C., Wolff, C., Glöer, P., and Wilke, T: Concurrent evolution of ancient sister lakes and sister species: the freshwater gastropod genus Radix in lakes Ohrid and Prespa, Hydrobiologia, 615, 157-167, 2008.

Allen, H. L. and Ocevski, B. T.: Limnological studies in a large, deep, oligotrophic lake (Lake Ohrid, Yugoslavia). A summary of nutritional radiobioassay responses of the pelagial phytoplankton, Arch. Hydrobiol., 53, 1-21, 1977.

Baho, D. L., Drakare, S., Johnson, R. K., Allen, C. R., and Angeler, D. G.: Similar resilience characteristics in lakes with different management practices, PLoS ONE, 9, e91881, doi:10.1371/journal.pone.0091881, 2014.

Barker, P., Williamson, D., Gasse, F., and Gibert, E.: Climatic and volcanic forcing revealed in a 50,000 year diatom record from Lake Massoko, Tanzania, Quaternary Res., 60, 368-376, 2003.

Baumgarten, H., Wonik, T., Tanner, D. C., Francke, A., Wagner, B., Zanchetta, G., Sulpizio, R., Giaccio, B., and Nomade, S.: Age depth-model for the past $630 \mathrm{ka}$ in Lake Ohrid (Macedonia/Albania) based on cyclostratigraphic analysis of downhole gamma ray data, Biogeosciences, 12, 7453-7465, doi:10.5194/bg-12-7453-2015, 2015.

Bond, G., Broecker, W., Johnsen, S., McManus, J., Labeyrie, L., Jouzel, J., and Bonani, G.: Correlations between climate records from North Atlantic sediments and Greenland ice, Nature, 365, 143-147, 1993.

Bray, J. R. and Curtis, J. T.: An ordination of upland forest communities of southern Wisconsin, Ecol. Monogr., 27, 325-349, 1957.

Carpenter, R. S.: Spatial signatures of resilience, Nature, 496, 308309, 2013.

Costa, A., Folch, A., Macedonio, G., Giaccio, B., Isaia, R., and Smith, V. C.: Quantifying volcanic ash dispersal and impact of the Campanian Ignimbrite super-eruption, Geophys. Res. Lett., 39, L10310, doi:10.1029/2012GL051605, 2012.

Cruces, F., Urrutia, R., Parra, O., Araneda, A., Treutler, H., Bertrand, S., Fagel, N., Torres, Le., Barra, R., and Chirinos, L.: Changes in diatom assemblages in an Andean lake in response to a recent volcanic event, Arch. Hydrobiol., 165, 23-35, 2006.

Cvetkoska, A., Reed, J. M., and Levkov, Z.: Diatoms as indicators of environmental change in ancient Lake Ohrid during the last glacial-interglacial cycle (ca $140 \mathrm{ka}$ ), in: Diatom Monographs, vol. 15, edited by: Witkowski, A., ARG Gartner Verlag, Ruggell, Liechtenstein, 220 pp., 2012.

Cvetkoska, A., Levkov, Z., Reed, J. M., and Wagner, B.: Late Glacial to Holocene climate change and human impact in the Mediterranean: the last ca. $17 \mathrm{ka}$ diatom record of Lake Prespa (Macedonia/Albania/Greece), Palaeogeogr. Palaeocl., 406, 22 32, 2014.

Cvetkoska, A., Jovanovska, E., Francke, A., Tofilovska, S., Vogel, H., Levkov, Z., Donders, T., Wagner, B., and Wagner-Cremer, F.: Ecosystem regimes and responses in a coupled ancient lake system from MIS 5b to present: the diatom record of lakes Ohrid and Prespa, Biogeosciences Discuss., 12, 15051-15086, doi:10.5194/bgd-12-15051-2015, 2015a.

Cvetkoska, A., Levkov, Z., Reed, J. M., Wagner, B., Panagiotopoulos, K., Leng, M., and Lacey, J.: Quaternary climate change and Heinrichs events in the southern Balkans: Lake Prespa diatom palaeolimnology from the last interglacial to present, J. Paleolimnol., 53, 215-231, 2015b.

D’Addabbo, M., Sulpizio, R., Guidi, M., Capitani, G., Mantecca, P., and Zanchetta, G.: Ash leachates from some recent eruptions of Mount Etna (Italy) and Popocateìpetl (Mexico) volcanoes and their impact on amphibian living freshwater organisms, Biogeosciences, 12, 7087-7106, doi:10.5194/bg-12-7087-2015, 2015.

De Vivo, B., Rolandi, G., Gans, P. B., Calvert, A., Bohrson, W. A., Spera, F. J., and Belkin, H. E.: New constraints on the pyroclastic eruptive history of the Campanian volcanic Plain (Italy), Miner. Petrol., 73, 47-65, 2001.

Fedele, F. G., Giaccio, B., Isaia, R., and Orsi, G.: The Campanian Ignimbrite eruption, Heinrich Event 4, and the Palaeolithic change in Europe: a high-resolution investigation, in: Volcanism and the Earth's Atmosphere, edited by: Robock, A. and Oppenheimer, C., Geophys. Monogr. Ser., vol. 139, American Geophysical Union, Washington, DC, 301-325, 2003.

Fitzsimmons, K. E., Hambach, U., Veres, D., and Iovita, R.: The Campanian Ignimbrite eruption: new data on volcanic ash dispersal and its potential impact on human evolution, PLoS ONE, 8, e65839, doi:10.1371/journal.pone.0065839, 2013.

Föller, K., Stelbrink, B., Hauffe, T., Albrecht, C., and Wilke, T.: Constant diversification rates of endemic gastropods in ancient Lake Ohrid: Ecosystem resilience likely buffers environmental fluctuations, Biogeosciences, 12, 7209-7222, doi:10.5194/bg12-7209-2015, 2015.

Francke, A., Wagner, B., Just, J., Leicher, N., Gromig, R., Baumgarten, H., Vogel, H., Lacey, J. H., Sadori, L., Wonik, T., Leng, M. J., Zanchetta, G., Sulpizio, R., and Giaccio, B.: Sedimentological processes and environmental variability at Lake Ohrid (Macedonia, Albania) between $640 \mathrm{ka}$ and present day, Biogeosciences Discuss., , 13, in press, 2016.

Grimm, E. C.: CONISS: a FORTRAN 77 program for stratigraphically constrained cluster analysis by the method of incremental sum of squares, Comput. Geosci., 13, 13-35, 1987.

Harper, M. A., Howorth, R., and Mcleod, M.: Late Holocene diatoms in Lake Poukawa: effects of airfall tephra and changes in depth, New Zeal. J. Mar. Fresh., 20, 107-118, 1986.

Holling, C.: Resilience and Stability of Ecological Systems, Ann. Rev. Ecolog. Syst., 4, 1-23, 1973.

Hoffmann, N., Reicherter, K., Fernández-Steeger, T., and Grützner, C.: Evolution of ancient Lake Ohrid: a tectonic perspective, Biogeosciences, 7, 3377-3386, doi:10.5194/bg-7-3377-2010, 2010.

Holling, C. S.: The resilience of terrestrial ecosystems: local surprise and global change, in: Sustainable Development of the Biosphere, edited by: Clark, W. C. and Munn, R. E., Cambridge University Press, London, 292-317, 1986.

Holm, N. P. and Armstrong, D. E.: Role of nutrient limitation and competition in controlling the populations of Asterionella formosa and Microcystis aeruginosa in semicontinuous culture, Limnol. Oceanogr., 24, 622-634, 1981.

Jovanovska, E., Nakov, T., and Levkov, Z.: Observations of the genus Diploneis from Lake Ohrid, Macedonia, Diatom Res., 28 237-262, 2013.

Juggins, S.: rioja: Analysis of quaternary science data, available at: http://cran.r-project.org/web/packages/cluster/index.html (last access: 11 August 2015), 2013.

Karabanov, E., Williams, D., Kuzmin, M., Sideleva, V., Khursevich, G., Prokopenko, A., Solotchina, E., Tkachenko, L., Fe- 
denya, S., Kerber, E., Gvozdkov, A., Khlustov, O., Bezrukova, E., Letunova, P., and Krapivina, S.: Ecological collapse of Lake Baikal and Lake Hovsgol ecosystems during the Last Glacial and consequences for aquatic species diversity, Palaeogeogr. Palaeoclimatol. Palaeoecol., 209, 227-243, doi:10.1016/j.palaeo.2004.02.017, 2004.

Kaufman, L. and Rousseeuw, P. J.: Finding groups in data: an introduction to cluster analysis, Wiley, New York, doi:10.1002/9780470316801, 1990.

Kilham, P., Kilham, S. S., and Hecky, R. E.: Hypothesized resource relationships among African planktonic diatoms, Limnol. Oceanogr., 31, 1169-1181, 1986.

Kostoski, G., Albrecht, C., Trajanovski, S., and Wilke, T.: A freshwater biodiversity hotspot under pressure - assessing threats and identifying conservation needs for ancient Lake Ohrid, Biogeosciences, 7, 3999-4015, doi:10.5194/bg-7-3999-2010, 2010.

Leicher, N., Zanchetta, G., Sulpizio, R., Giaccio, B., Wagner, B., Nomade, S., and Francke, A.: First tephrostratigraphic results of the DEEP site record in Lake Ohrid, Macedonia, Biogeosciences Discuss., 12, 15411-15460, doi:10.5194/bgd-1215411-2015, 2015.

Leng, M. J., Wagner, B., Aufgebauer, A., Panagiotopoulos, K., Vane, C., Snelling, A., Haidon, C., Woodley, E., Vogel, H., Zanchetta, G., Sulpizio, R., and Baneschi, I.: Understanding past climatic and hydrological variability in the Mediterranean from Lake Prespa sediment isotope and geochemical record over the last glacial cycle, Quaternary Sci. Rev., 66, 123-136, 2013.

Levkov, Z. and Williams, D. M.: Fifteen new diatom (Bacillariophyta) species from Lake Ohrid, Macedonia, Phytotaxa, 30, 141, 2011.

Levkov, Z. and Williams, D. M.: Checklist of diatoms (Bacillariophyta) from Lake Ohrid and Lake Prespa (Macedonia), and their watersheds, Phytotaxa, 45, 1-76, 2012.

Levkov, Z., Krstic, S., Metzeltin, D., and Nakov, T.: Diatoms of Lakes Prespa and Ohrid. About 500 taxa from ancient lake system, in: Iconographia Diatomologica, vol. 16, ARG Gartner Verlag, Ruggell, Liechtenstein, 603 pp., 2007.

Lindhorst, K., Krastel, S., Papenberg, C., and Heidarzadeh, M.: Modeling submarine landslide-generated waves in Lake Ohrid, Macedonia/Albania, Adv. Nat. Technol. Haz., 37, 497-506, 2014.

Lindhorst, K., Krastel, S., Reicherter, K., Stipp, M., Wagner, B., and Schwenk, T.: Sedimentary and tectonic evolution of Lake Ohrid (Macedonia/Albania), Basin Res., 27, 84-101, 2015.

Maechler, M., Rousseeuw, P., Struyf, A., Hubert, M., and Hornik, $\mathrm{K}$ : cluster: cluster analyses basics and extensions, available at: http://cran.r-project.org/web/packages/cluster/index.html (last access: 11 August 2015), 2013.

Matzinger, A. and Schmid, M.: Eutrophication of ancient Lake Ohrid: global warming amplifies detrimental effects of increased nutrient inputs, Limnol. Oceanogr., 52, 338-353, 2007.

Matzinger, A., Jordanoski, M., Veljanoska-Sarafiloska, E., Sturm, M., Müller, B., and Wüest, A.: Is Lake Prespa jeopardizing the ecosystem of Ancient Lake Ohrid?, Hydrobiologia, 553, 89-109, 2006a.

Matzinger, A., Spirkovski, Z., Patceva, S., and Wüest, A.: Sensitivity of ancient Lake Ohrid to local anthropogenic impacts and global warming, J. Great Lakes Res., 32, 158-179, 2006 b.
Niemi, G. J., DeVore, P., Detenbeck, N., Taylor, D., Lima, A., Pastor, J., Yount, D. J., and Naiman, R. J.: Overview of case studies on recovery of aquatic systems from disturbance, Environ. Manage., 14, 571-587, 1990.

Panagiotopoulos, K., Böhm, A., Leng, M., Wagner, B., and Schäbitz, F.: Climate variability over the last $92 \mathrm{ka}$ in SW Balkans from analysis of sediments from Lake Prespa, Clim. Past, 10, 643660, doi:10.5194/cp-10-643-2014, 2014.

Pavlov, A., Levkov, Z., Williams, D. M., and Edlund, M. E.: Observations on Hippodonta (Bacillariophyceae) in selected ancient lakes, Phytotaxa, 90, 1-53, 2013.

$\mathrm{R}$ Core Team: R: a language and environment for statistical computing. R Foundation for Statistical Computing, Vienna, Austria, available at: http://www.R-project.org, last access: $11 \mathrm{Au}-$ gust 2015.

Reed, J. M., Cvetkoska, A., Levkov, Z., Vogel, H., and Wagner, B.: The last glacial-interglacial cycle in Lake Ohrid (Macedonia/Albania): testing diatom response to climate, Biogeosciences, 7, 3083-3094, doi:10.5194/bg-7-3083-2010, 2010.

Renberg, I.: A procedure for preparing large sets of diatom slides from sediment cores, J. Paleolimnol., 4, 87-90, 1990.

Scheffer, M. and Carpenter, S.: Catastrophic regime shifts in ecosystems: linking theory to observation, Trends Ecol. Evol., 18, 648656, 2003.

Schneider, S. C., Cara, M., Eriksen, T. E., Goreska, B. B., Imeri, A., Kupe, L., Lokoska, T., Patceva, S., Trajanovska, S., Trajanovski, S., Talevska, M., and Sarafiloska, E. V.: Eutrophication impacts littoral biota in Lake Ohrid while water phosphorus concentrations are low, Limnologica, 44, 90-97, 2014.

Spanbauer, T. L., Allen, C. R., Angeler, D. G., Eason, T., Fritz, S. C., Garmestani, A. S., Nash, K. L., and Stone, J. R.: Prolonged instability prior to a regime shift, PLoS ONE, 9, e108936, doi:10.1371/journal.pone.0108936, 2014.

Stanković, S.: The Balkan Lake Ohrid and its living world, Monogr. Biol. IX, Uitgeverij Dr. W. Junk, Den Haag, The Netherlands, 1960.

Sulpizio, R., Zanchetta, G., D’Orazio, M., Vogel, H., and Wagner, B.: Tephrostratigraphy and tephrochronology of lakes Ohrid and Prespa, Balkans, Biogeosciences, 7, 3273-3288, doi:10.5194/bg7-3273-2010, 2010.

Telford, R. J., Barkerb, P., Metcalfec, S., and Newtond, A.: Lacustrine responses to tephra deposition: examples from Mexico, Quaternary Sci. Rev., 23, 2337-2353, 2004.

Urrutia, R., Araneda, A., Cruces, F., Torres, L., Chirinos, L., Treutler, H. C., Fagel, N., Bertrand, S., Alvial, I., Barra, R., and Chapron, E.: Changes in diatom, pollen, and chironomid assemblages in response to a recent volcanic event in Lake Galletué (Chilean Andes), Limnologica, 37, 49-62, 2007.

Vogel, H., Wagner, B., Zanchetta, G., Sulpizio, R., and Rosén, P.: A paleoclimate record with tephrochronological age control for the last glacial-interglacial cycle from Lake Ohrid, Albania and Macedonia, J. Paleolimnol., 44, 295-310, 2010a.

Vogel, H., Wessels, M., Albrecht, C., Stich H.-B., and Wagner, B.: Spatial variability of recent sedimentation in Lake Ohrid (Albania/Macedonia), Biogeosciences, 7, 3333-3342, doi:10.5194/bg7-3333-2010, 2010b.

Wagner, B., Reicherter, K., Daut, G., Wessels, M., Matzinger, A., Schwalb, A., Spirkovski, Z., and Sanxhaku, M.: The potential of 
Lake Ohrid for long-term palaeoenvironmental reconstructions, Palaeogeogr. Palaeocl., 259, 341-356, 2008.

Wagner, B., Vogel, H., Zanchetta, G., and Sulpizio R.: Environmental changes on the Balkans recorded in the sediments from lakes Prespa and Ohrid, Biogeosciences, 7, 3365-3392, doi:10.5194/bg-7-3187-2010, 2010.

Wagner, B., Aufgebauer, A., Vogel, H., Zanchetta, G., Sulpizio, R., and Damaschke, M.: Late Pleistocene and Holocene contourite drift in Lake Prespa (Albania/F.Y.R. of Macedonia/Greece), Quaternary Int., 274, 112-121, 2012a.

Wagner, B., Francke, A., Sulpizio, R., Zanchetta, G., Lindhorst, K., Krastel, S., Vogel, H., Rethemeyer, J., Daut, G., Grazhdani, A., Lushaj, B., and Trajanovski, S.: Possible earthquake trigger for 6th century mass wasting deposit at Lake Ohrid (Macedonia/Albania), Clim. Past, 8, 2069-2078, doi:10.5194/cp-8-20692012, 2012b.

Wagner, B., Wilke, T., Krastel, S., Zanchetta, G., Sulpizio, R., Reicherter, K., Leng, M., Grazhdani, A., Trajanovski, S., Francke, A., Lindhorst, K., Levkov, Z., Cvetkoska, A., Reed, J. M., Zhang, X., Lacey, J., Wonik, T., Baumgarten, H., and Vogel, H.: The SCOPSCO drilling project recovers more than 1.2 million years of history from Lake Ohrid, Sci. Dril., 17, 19-29, 2014.

Watzin, M. C., Puka, V., and Naumoski, T. B.: Lake Ohrid and its watershed: state of the environment report, Lake Ohrid Conservation Project, Tirana, Albania and Ohrid, Macedonia, 2002.
Wutke, K., Wulf, S., Tomlinson, L. E., Hardiman, M., Dulski, P., Luterbacher, J., and Brauer, A.: Geochemical properties and environmental impacts of seven Campanian tephra layers deposited between 40 and $38 \mathrm{ka} \mathrm{BP}$ in the varved lake sediments of Lago Grande di Monticchio, southern Italy, Quaternary Sci. Rev., 118, 67-83, 2015

Zhang, X., Reed, J. M., Lacey, J. H., Francke, A., Leng, M. J., Levkov, Z., and Wagner, B.: Complexity of diatom response to Lateglacial and Holocene climate and environmental change in ancient, deep, and oligotrophic Lake Ohrid (Macedonia/Albania), Biogeosciences Discuss., 13, in press, 2016. 